\title{
Günter Stemberger
}

\section{Judaica Minora}

\author{
Teil I: Biblische Traditionen im rabbinischen Judentum
}

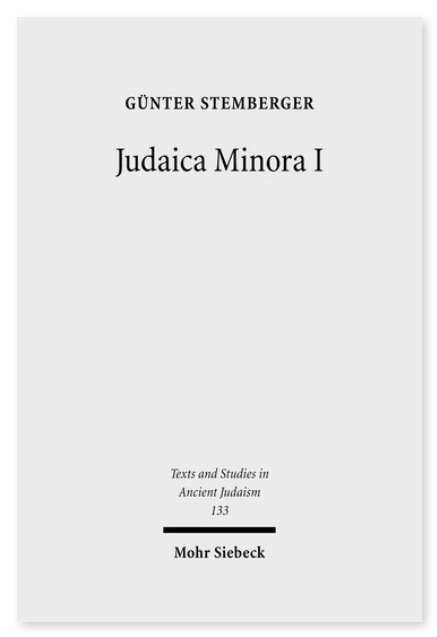

2010. VIII, 560 Seiten. TSAJ 133

ISBN 978-3-16-151466-1

DOI 10.1628/978-3-16-151466-1

eBook PDF $194,00 €$

ISBN 978-3-16-150403-7

Leinen $194,00 €$
Die Aufsätze dieses Bandes entstanden in den letzten zwanzig Jahren. Im Mittelpunkt steht das rabbinische Verständnis der Tora und ihre Stellung im jüdischen Leben, die Frage nach dem Kanon und der rabbinischen Hermeneutik. Konkretisiert wird die Thematik in Aufsätzen zur rabbinischen Auslegung einzelner biblischer Texte oder Bücher einschließlich der Makkabäerbücher und des Buches Judit, aber auch in Studien zur Darstellung biblischer Themen in den Synagogen der Zeit. Mehrere Aufsätze befassen sich mit den Strömungen im palästinischen Judentum der Spätzeit des Zweiten Tempels, der Frage nach einer möglichen Einheit in einem Mainstream Judaism und der Entstehung des Christentums aus diesem gemeinsamen Boden. Wieweit die Zeit des Zweiten Tempels im rabbinischen Judentum nachwirkt, wird in verschiedenen Aufsätzen angesprochen. Drei Aufsätze befassen sich mit den Vorstellungen vom Priestertum und von der himmlischen Liturgie in der Zeit nach dem Untergang des Tempels. Die letzte Gruppe von Aufsätzen ist dem Gemeinsamen und den Unterschieden in jüdischer und christlicher Auslegung der Bibel gewidmet, auch der Polemik, die sich aus der Rivalität um den gemeinsamen Text ergibt. Was Judaistik und neutestamentliche Forschung voneinander lernen können, ist Thema des abschließenden Aufsatzes.

Alle Beiträge wurden soweit möglich formal vereinheitlicht, Überschneidungen getilgt, im Einzelfall auch zwei ursprünglich selbständige Aufsätze ineinander verschmolzen. Ursprünglich auf Französisch oder Italienisch erschienene Aufsätze wurden übersetzt und alle Arbeiten zumindest in einem gewissen Umfang auf den heutigen Stand gebracht.

Günter Stemberger Geboren 1940; Studien der kathol. Theologie und Judaistik; 1967 Promotion; 1974 Habilitation; $1977-$ 2009 Professor für Judaistik an der Universität Wien; 2005 Dr. theol. h.c. der Universität Göttingen; seit Oktober 2009 emeritiert.
Jetzt bestellen:

https://mohrsiebeck.com/buch/judaica-minora-9783161514661?no_cache=1

order@mohrsiebeck.com

Telefon: +49 (0)7071-923-17

Telefax: $+49(0) 7071-51104$ 